\title{
Iron-Catalyzed Cross-Coupling of Thioesters and Organomanganese Reagents
}

\author{
Valentin Jacob Geiger, ${ }^{[a]}$ and Ivana Fleischer ${ }^{*[a]}$ \\ Dedicated to Prof. Dr. Martin E. Maier on the occasion of his 65 . birthday
}

[a] V. J. Geiger, Prof. Dr. I. Fleischer

Institute of Organic Chemistry

Faculty of Mathematics and Natural Sciences,

Eberhard Karls University Tübingen

Auf der Morgenstelle 18, 72076 Tübingen, Germany

E-mail: ivana.fleischer@uni-tuebingen.de

Supporting information for this article is given via a link at the end of the document.

\begin{abstract}
We report a Fukuyama-type coupling of thioesters with aliphatic organomanganese reagents utilizing a cheap and easily available iron(III) catalyst. The reactions exhibit a wide tolerance of solvents and functional groups (e.g. ketones, esters, aryl(pseudo)halides) allowing for the conversion of thioesters derived from natural products and pharmaceutical compounds. Investigations showed a strong steric influence from each reaction component (carboxylic moiety, thiol substituent and manganese reagent), which enabled regioselective transformation of dithioesters. Tandem transformations combining the coupling with an additional step were observed. Our experiments provide insights into the potential of the employed aliphatic manganese reagents, such as the interaction between iron, manganese and oxygen, which allows for a smooth conversion
\end{abstract}

\section{Introduction}

The palladium-catalyzed reaction between thioesters ${ }^{[1]}$ and organozinc reagents, generally known as Fukuyama crosscoupling (FCC), ${ }^{[2]}$ constitutes a convenient method for the synthesis of ketones, as demonstrated by numerous synthetic applications ${ }^{[3]}$ Besides variations of the palladium catalyst, ${ }^{[4]}$ other transition metals such as the non-precious nickel ${ }^{[5]}$ or cobalt ${ }^{[6]}$ were employed. For the transmetalation step, other less polar reagents such as arylboronic acids introduced by Liebeskind and Srog ${ }^{[7]}$ or siloxanes reported by Van der Eycken ${ }^{[8]}$ require the presence of stoichiometric amounts of copper in addition to the palladium-based catalyst. To date, couplings using organoboronates,$^{[9]}$-stannanes ${ }^{[10]}$ and -indium reagents ${ }^{[11]}$ were developed for palladium-based catalysts.

Notwithstanding the utility of the Fukuyama coupling, its applicability is generally limited to the availability and reactivity of respective organozinc reagents. The reactions may proceed sluggishly, be in need of stochiometric additives (e.g. Zn(II) salts for the conversion of secondary alkyl reagents) ${ }^{[12]}$ or even succumb to competing side-product formation. Another liability of zinc organyl compounds was exemplified in our previous studies on their Ni-catalyzed coupling with thioesters, wherein aliphatic zinc reagents showed no reactivity. ${ }^{[5 c]}$ While more reactive Grignard reagents could resolve the issue of low reactivity of zinc reagents under non-precious metal catalysis, the functional group tolerance would be drastically diminished. ${ }^{[13]}$ With these caveats in mind, an intermediary reactivity between Grignard and organozinc reagents was sought after. This led us to consider the use of organomanganese reagents, which possess a reportedly good functional group tolerance combined with a generally higher reactivity than their zinc analogues. ${ }^{[14]}$ In early works, the reactivity of such "manganese Grignard reagents" was mainly studied in non-catalytic reactions or in Cu-catalyzed couplings. ${ }^{[15]}$ To the best of our knowledge, only one example of an ironcatalyzed cross-coupling has been reported in this time frame (before 2000). ${ }^{[16]}$

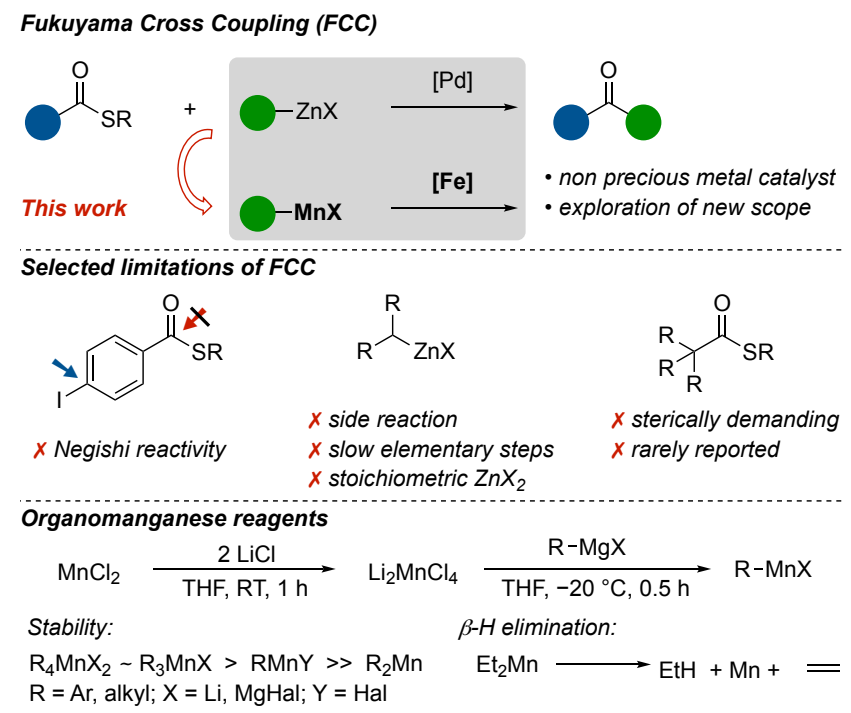

Scheme 1. Fukuyama cross-coupling and our iron-catalyzed coupling of organomanganese reagents.

In contrast, more recent publications contain examples of inviolate potential of e.g. aryl manganese compounds or other stabilized manganese reagents in transition metal-catalyzed reactions utilizing Fe or Ni-catalysts. ${ }^{[17]}$ For clarity, the employed reagents can be considered stabilized, since they were unable to undergo $\beta$-hydrogen elimination, which is a main decomposition pathway. ${ }^{[18]}$ Another important feature of these reagents is their property to form higher substituted manganates $\left(\mathrm{LiMnR}_{3}\right.$ or $\mathrm{Li}_{2} \mathrm{MnR}_{4}$ ), which led to the recent discovery of a tandem Mn-I exchange/homocoupling, a reactivity thought to be reserved for $\mathrm{RLi}$ or RMgX reagents. ${ }^{[19]}$ These literature examples not only elucidate the high complexity of manganese organyles but also inspire further studies of their so far less known potential. Our herein presented methodology of a base metal-catalyzed cross-coupling reaction of $\beta$-hydrogen containing aliphatic organomanganese 
reagents with thioesters furnishing highly functionalized building blocks extends the known synthetic scope of these reagents.

\section{Results and Discussion}

On the basis of previous literature, aliphatic manganese reagents were synthesized by treating Grignard reagent with $\mathrm{MnCl}_{2} \cdot 2 \mathrm{LiCl}^{[17 \mathrm{a}]}$ In the model reaction, thioester 1 a reacted with ethyl manganese bromide lithium chloride complex in the presence of potential catalysts (Table 1). Various transition metal salts provided the product 3aa in low to moderate yields (Entries 2-6).

Table 1. Optimization of reaction conditions for the synthesis of octan-3-one. ${ }^{[a]}$

\begin{tabular}{|c|c|c|c|c|c|}
\hline & $\begin{array}{r}+\widehat{2 a(1} \\
{[0.25} \\
\end{array}$ & $\begin{array}{l}\text { InBre LiCl } \\
\text { equiv) } \\
\text { in THF] }\end{array}$ & $\begin{array}{r}\text { [cat] } \\
\text { solvent } \\
-20^{\circ} \mathrm{C}, 10\end{array}$ & & $\underbrace{O}_{3 a a}$ \\
\hline Entry & Catalyst & Solven & & $\begin{array}{l}\text { Conv. } \\
{[\%]^{[c]}}\end{array}$ & $\begin{array}{l}\text { Yield } \\
{[\%]^{[c]}}\end{array}$ \\
\hline 1 & none & THF & & 18 & 0 \\
\hline 2 & $\mathrm{Ni}(\operatorname{acac})_{2}$ & THF & & 95 & 52 \\
\hline 3 & $\mathrm{CoCl}_{2}{ }^{[\mathrm{d}]}$ & THF & & 81 & 64 \\
\hline 4 & Cul[d] & THF & & 44 & 37 \\
\hline 5 & $\mathrm{Pd}\left(\mathrm{PPh}_{3}\right) \mathrm{Cl}_{2}$ & THF & & 26 & 18 \\
\hline 6 & $\mathrm{Mn}(\mathrm{acac})_{3}$ & THF & & 62 & 5 \\
\hline 7 & $\mathrm{FeCl}_{2}{ }^{[\mathrm{d}]}$ & THF & & 92 & 82 \\
\hline 8 & $\mathrm{Fe}(\mathrm{acac})_{2}$ & THF & & Quant & 89 \\
\hline 9 & $\mathrm{FeCl}_{3}^{[\mathrm{d}]}$ & THF & & Quant & 84 \\
\hline 10 & $\left(\mathrm{FeCl}_{3}\right)_{2}(\text { tmeda })_{3}$ & THF & & Quant & 89 \\
\hline 11 & $\mathrm{Fe}(\mathrm{acac})_{3}$ & THF & & Quant. & 91 \\
\hline 12 & $\mathrm{Fe}(\mathrm{acac})_{3}$ [e] & THF & & Quant & 86 \\
\hline 13 & $\mathrm{Fe}(\mathrm{acac})_{3}$ & THF/Et & & Quant & 88 \\
\hline 14 & $\mathrm{Fe}(\mathrm{acac})_{3}$ & $\mathrm{THF} / 1$, & -dioxane $e^{[f]}$ & 98 & 90 \\
\hline 15 & $\mathrm{Fe}(\mathrm{acac})_{3}$ & THF/Et & DAc & Quant. & 92 \\
\hline 16 & $\mathrm{Fe}(\mathrm{acac})_{3}$ & THF/NI & & 90 & 84 \\
\hline 17 & $\mathrm{Fe}(\mathrm{acac})_{3}$ & THF/DC & & 83 & 71 \\
\hline 18 & $\mathrm{Fe}(\mathrm{acac})_{3}$ & THF $(\mathrm{O}$ & & Quant. & $98\left(78^{[\mathrm{h}]}\right)$ \\
\hline
\end{tabular}

[a] Reaction conditions: thioester $(53.4 \mathrm{mg}, 333 \mu \mathrm{mol}, 1$ equiv. $), \mathrm{EtMnBr} \cdot \mathrm{LiC}$ (400 $\mu \mathrm{mol}, 1.2$ equiv. based on titre, usually $\leq 0.28 \mathrm{M}$ in THF), [catalyst] (5 mol\%), dry THF $(1 \mathrm{~mL}),-20{ }^{\circ} \mathrm{C}, 10 \mathrm{~min}$. [b] Mixture: THF/co-solvent $=8: 5$ (v/v). [c] Determined by quantitative GC-FID using pentadecane as internal standard. [d] $10 \mathrm{~mol} \%$. [e] $1 \mathrm{~mol} \%$. [f] Slurry due to melting point of the cosolvent. [g] Solvent has not been degassed. [h] Isolated yield.

To our delight, the use of broadly available iron catalysts resulted early on in quantitative conversions and very good yields (Entries 7-10), especially with iron(III) acetylacetonate (acac) (Entry 11). Slightly decreased yield was obtained using only
$1 \mathrm{~mol} \%$ of catalyst, which corresponds to turnover frequency of $516 \mathrm{~h}^{-1}$ (Entry 12). The reaction can be performed in almost any ethereal solvent with very good yields as well as in EtOAc (Entries 13-15). Highly polar co-solvents such as $\mathrm{N}$-methyl pyrrolidone (NMP) showed a slightly decreased yield (Entry 16). This is in contrast to literature observations in iron-catalyzed Kumada cross-couplings of aryl halides with organomanganese and organomagnesium reagents, which usually perform better with NMP. ${ }^{[16,20]}$ Surprisingly, almost quantitative yields were obtained by using non-degassed THF (Entry 18). In contrast, the reaction performs poorly if set up under air conditions. Based on previous studies, we assumed the favourable presence of oxygen on the formation of a potential oxo-mangenese species, which increases yields if present in traces. ${ }^{[21]}$ The somewhat lower isolated yield of 3aa was attributed to its volatility.

The performance of organomanganese reagents was more efficient compared to other organometallic compounds under identical reaction conditions (Scheme 2), e.g. to organozinc reagents, which furnished no product, and also to Grignard reagents leading to moderate results. Addition of $10 \mathrm{~mol} \%$ of $\mathrm{MnCl}_{2} \cdot 2 \mathrm{LiCl}$ to a reaction set up with Grignard reagent didn't resolve this issue. Furthermore, a preliminary screening showed an influence of the thioester thiol moiety on the conversion (prim Ar>sec >>tert). The 1,2-addition was never observed in the coupling of organomanganese reagents under the applied conditions for standard substrate, even if 3aa was exposed to the reaction conditions.

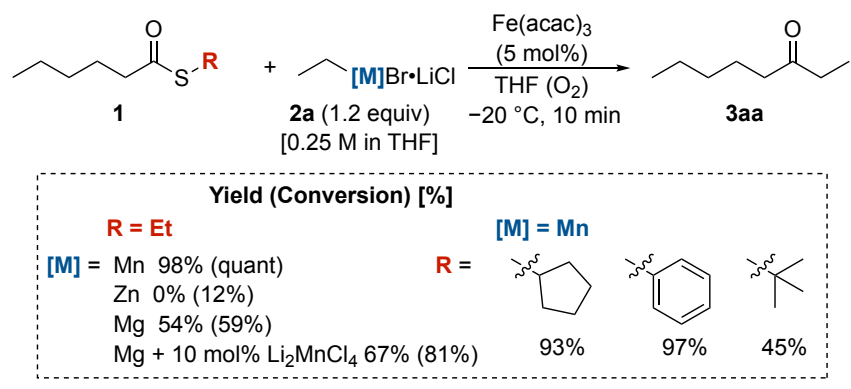

Scheme 2. Iron-catalyzed Fukuyama cross-coupling with different transmetalating reagents and varying S-substituents.

On the basis of this initial screening, a series of S-ethyl thioesters was subjected to the coupling with ethylmanganese bromide (Scheme 3). Primary thioesters were converted in good to excellent yields to the products $\mathbf{3 b a - f a}$, including the sterically demanding 3,3,3-triphenyl substituted substrate 1f. A more significant steric influence on the reaction stems from the $\alpha$ substitution of the thioester (prim>sec cyclic $_{\text {stert }>s e c)}$ ). The complete breakdown of reactivity of the secondary substrate $\mathbf{1 g}$ and similar aliphatic compounds contrasted with other secondary thioesters having an $\alpha$-methyl group (1k), an $\alpha$-phenyl group (1j) or being cyclic $(\mathbf{1 h}, \mathbf{1 i}, \mathbf{1}, \mathbf{1} \mathbf{m})$, which all underwent the transformation with moderate to excellent yields. Experiments conducted showed that the unreactive $\mathbf{1 g}$ didn't poison or slow down the conversion of primary thioester $\mathbf{1 b}$, yet, $\mathbf{1} \mathbf{j}$ did.

The reaction performed comparably well on a higher scale as exemplified for $3 \mathbf{b a}$. The diastereomeric ratio of $1 \mathrm{~h}, 1 \mathrm{l}$ and $1 \mathrm{~m}$ (as pure endo diastereomer or 5:3 endo:exo mixture) remained unchanged. Worth mentioning is the successful synthesis of benzylic ketones $\mathbf{3 e a}$ and $\mathbf{3 j a}$ in good yields without decarbonylation products being detected via GC-MS. This 
indicates that formation of acyl radicals is unlikely, or their recombination with the metal centre is faster than a potential decarbonylation step. A noteworthy selectivity towards catalytic conversion of the thioester moiety was observed with substrates containing a keto and ester functionality leading to products 3oa and 3pa in good yields. $\alpha$-Ketothioesters were not tolerated but showed traces of decarbonylation products, which we were unable to isolate.

In our previous studies on a nickel-catalyzed FCC, we were unable to use benzoic acid derived thioesters. ${ }^{[5 c]}$ Gratifyingly, several aromatic thioesters with $o_{-}, m-$, and $p$-substituents performed well in the coupling reaction. (Pseudo-)halides were tolerated under the reaction conditions and the products $3 \mathbf{w a}-\mathbf{B a}$ were furnished in fair to good yields showing only traces of side products resulting from the oxidative addition into the $\mathrm{C}-\mathrm{X}$ bond. Especially, the tolerance of aryl iodides (3za) should be highlighted, since this is usually difficult for palladium-catalyzed cross-coupling reactions due to the competing occurrence of Negishi coupling ${ }^{[4 \mathrm{~b}]}$ Moreover, similar reactivity in iron-catalyzed $s p^{2}-s p^{3}$-cross coupling is known for Grignard reagents, though in the presence of NMP. ${ }^{[20 b]}$ The reaction doesn't tolerate highly redox-active functionalities such as nitro-groups. Compounds containing a sterically unhindered nitrile-group (e.g. 3Ca) didn't furnish product, which might be attributed to a coordination of the functional group to the active catalyst. This claim was substantiated with the addition of the thioester $1 \mathrm{C}$ to the synthesis of $3 \mathrm{aa}$, which reduced the yield. In contrast, 3 La could be converted, which can be explained either by the overall higher complexity of the substrate or by the steric hinderance in the 0 position to the nitrile group. A methyl group on the aromatic ring did not affect the results much, only in the case of the sterically more demanding ortho-substituted thioester, a lower yield was obtained for the product 3Fa. Interestingly, the employed metasubstituted benzoic acid thioesters 3ra and 3sa showed low yields or only traces of product, depending on the electronic properties of the substituent. It should also be noted that heterocyclic cores, which might coordinate to metal and thus hinder the reaction, were tolerated in this case (products $3 \mathrm{Ea}$ and $\mathbf{3} \mathbf{c a}$ ). The promising high tolerance of various functionalities led us to test the coupling of thioesters derived from natural or pharmaceutical compounds. Thus, thioesters of citronellic acid $\mathbf{1 H}$, oleic acid $\mathbf{1 I}$, dehydrocholic acid $1 \mathrm{~J}$, acefylline $1 \mathrm{~K}$, febuxostat $1 \mathrm{~L}$ could be converted in moderate to excellent yields.

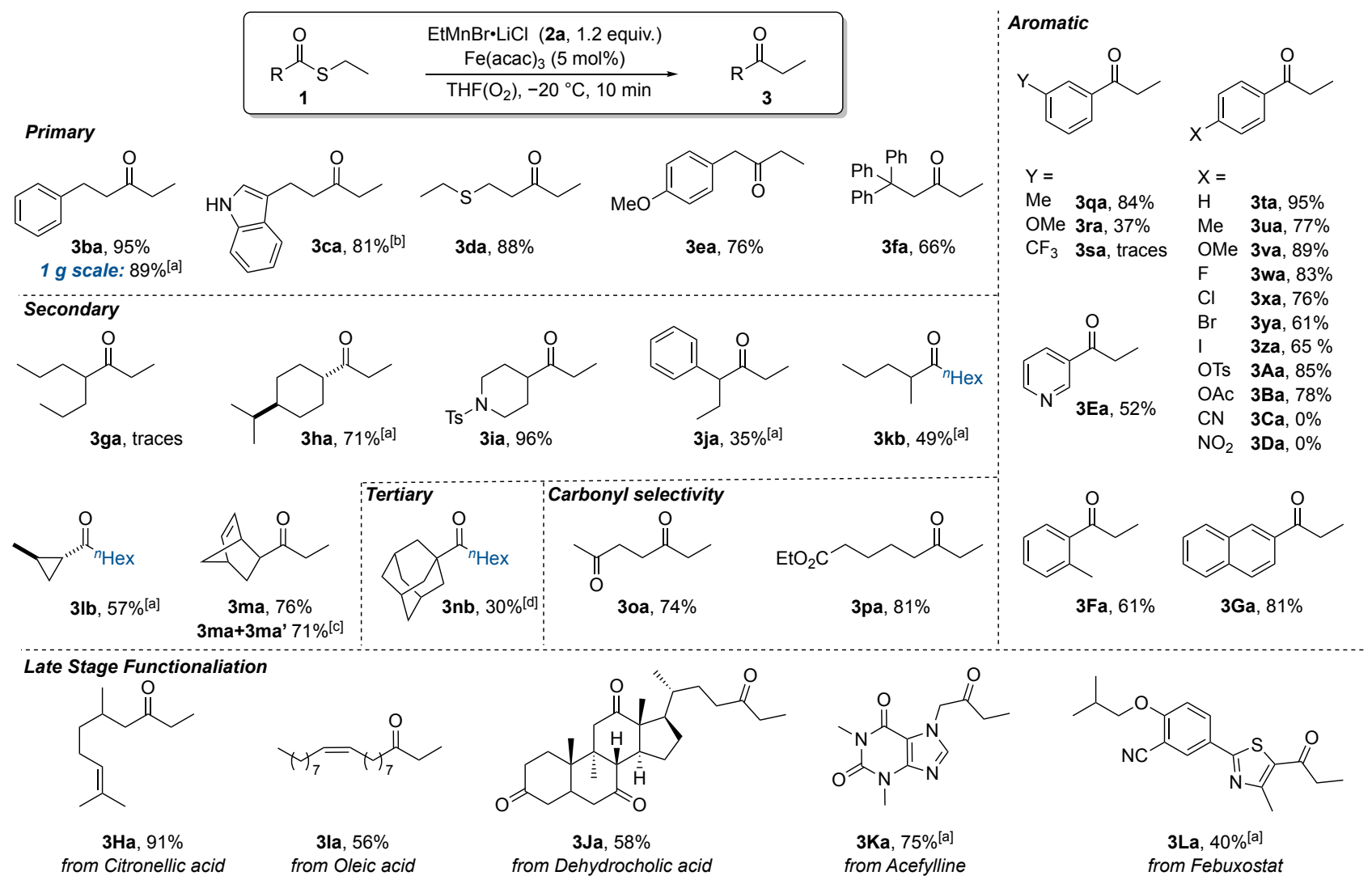

Scheme 3. Coupling of various thioesters with ethyl manganese bromide. Isolated yields are given unless stated otherwise. Standard reaction conditions: thioester ( $1 \mathrm{mmol}, 1$ equiv.), EtMnBr $\mathrm{LiCl}(1.2 \mathrm{mmol}, 1.2 \text { equiv. based on titre, usually } \leq 0.3 \mathrm{M} \text { in THF), Fe(acac) })_{3}(17.7 \mathrm{mg}, 50 \mu \mathrm{mol}, 0.05 \mathrm{equiv}$.), dry THF (1 mL, not degassed), $-20^{\circ} \mathrm{C}, 10 \mathrm{~min}$. [a] $15 \mathrm{~min}$. [b] EtMnBr$\cdot \mathrm{LiCl}(2.2 \mathrm{mmol}, 2.2$ equiv. based on titre, usually $\leq 0.3 \mathrm{M}$ in THF $)$. [c] Mixture of isomers: endo/exo $=5: 3$. [d] NMR yield.

In addition, a useful regioselective coupling was demonstrated for sterically differentiated thioester 4 (Scheme 4). A selective mono-coupling of the primary thioester moiety was achieved by using 1.2 equivalents of the transmetalating reagent providing $\mathbf{5}$ in $62 \%$ yield. Whereas 2.2 equivalents of $2 \mathrm{a}$ led to coupling of both thioesters to yield $79 \%$ of diketone 6 after slightly longer reaction time. Similar experiments were not possible with dithioesters containing an $\alpha$-phenyl-group due to low conversion, which can be explained by a supressing effect of the $\alpha$-phenylgroup. 


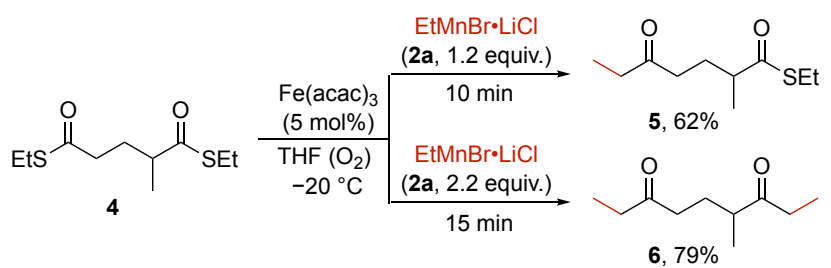

Scheme 4. Selective mono- or double-coupling of dithioester 4.

The reaction was also employed in the synthesis of dihydrojasomone, furnishing the precursor undecane-2,4-dione (3ob) in very good yield (Scheme 5). The diketone was then further converted to the natural product 7 by an aldol reaction known from previously described synthesis. ${ }^{[22]}$
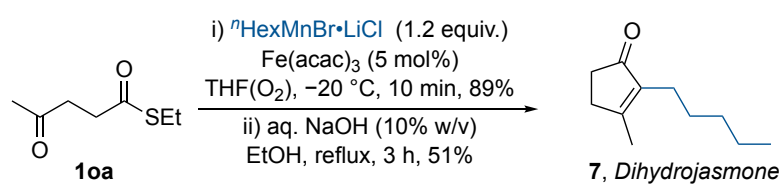

Scheme 5. Synthesis of the natural compound dihydrojasmone.

Furthermore, a sequential reactivity was observed for the conversion of thioester derived from 2-fluorobenzoic acid yielding 9, which formed though concurrent activation of the C-S and C-F bonds (Scheme 6a). This strategy was used to install alkyl chains in both ortho-positions to furnish ketone 11 (Scheme 6b). This was found to be applicable to every ortho-halide substituted thioester. Similar reactivity was reported for organolithium reagents. ${ }^{[23]}$ Upon subjecting Diclofenac to the reaction conditions, the sequential coupling/enamine formation was observed, leading to a functionalized indole derivative 13 (Scheme 6c). Notably, no side reaction from the $\mathrm{C}-\mathrm{Cl}$ bond activation occurred.

FCC/Kumada

a)<smiles>CCSC(=O)c1ccccc1F</smiles>

8<smiles>CC[R]C(=O)c1c(F)c(F)c(F)c(F)c1F</smiles>

10

FCC/enamine formation<smiles>O=C([Se])Cc1ccccc1Nc1c(Cl)cccc1Cl</smiles>

12

$$
\begin{aligned}
& \text { EtMnBr} \cdot \mathrm{LiCl}(2.2 \text { equiv. }) \\
& \underset{\mathrm{Fe}(\mathrm{acac})_{3}(5 \mathrm{~mol} \%)}{\mathrm{THF}\left(\mathrm{O}_{2}\right),-20^{\circ} \mathrm{C}, 30 \mathrm{~min}}
\end{aligned}
$$

$$
\begin{aligned}
& { }^{n} \mathrm{HexMnBr} \bullet \mathrm{LiCl}(3.2 \text { equiv. }) \\
& \underset{\mathrm{Fe}(\mathrm{acac})}{\mathrm{THF}\left(\mathrm{O}_{2}\right),-20{ }^{\circ} \mathrm{Col}, 30 \text { min }}
\end{aligned}
$$

EtMnBr•LiCl (2.2 equiv.) $\mathrm{Fe}(\mathrm{acac})_{3}(5 \mathrm{~mol} \%)$ $\operatorname{THF}\left(\mathrm{O}_{2}\right),-20^{\circ} \mathrm{C}, 15 \mathrm{~min}$

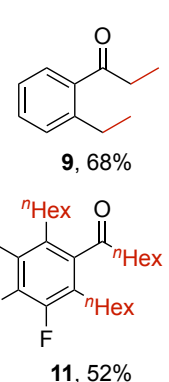

$11,52 \%$

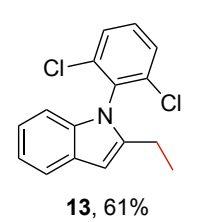

Scheme 6. Isolated products of sequential transformations initiated by the cross-coupling.

Next, we explored the performance of different organomanganese reagents (Scheme 6). As expected, chain length of non-branched aliphatic organomanganese reagents had only a weak influence on reaction performance, as ketones $\mathbf{3 b c}$ and 3 bd were obtained in very good yields. For the successful synthesis of $\mathbf{3 b d}$ the reagent originated from the organolithium analogue. It can therefore be assumed that the reaction is independent on any $\mathrm{Mg}^{2+}$-cations from the Grignard precursor. Also, secondary organomanganese reagents $2 \mathrm{e}$ and $\mathbf{2 f}$ were converted with high yields of $90 \%$ and $87 \%$. tert-Butyl manganese bromide only led to traces of product, which was reasoned by its steric bulk. The homobenzylic ketone $\mathbf{3 b g}$ was obtained in fair yield.

(5be)

Scheme 7. Variation of the organomanganese reagent in the coupling with thioester $\mathbf{1 b}$.

With this in mind, the role of the transmetalating reagent was assumed to be depended on its ability to undergo $\beta$-hydrogen elimination. ${ }^{[18]}$ Surprisingly, reactivity was observed with benzyl manganese halide as reagent, although in poor yield and with high amounts of bibenzyl as homocoupling side product. This is in line with the results from iron-catalyzed cross-coupling of comparable Grignard reagents $(\mathrm{Ph}, \mathrm{Bn})$. These usually require a ligand or additive depending on the electronic properties of the coupling compounds. ${ }^{[2]}$ To this end, experiments employing methyl- or phenyl-manganese reagent performed only poorly, which couldn't be resolved by utilizing polyarylmanganates. The reaction of manganese reagent possessing sterically shielded $\beta$ hydrogen atoms yielded only traces of product $3 \mathrm{bi}$ under standard conditions. However, the reaction could be observed at $0{ }^{\circ} \mathrm{C}$ for $1 \mathrm{~h}$. Functionalities such as double bond or acetal were tolerated, as demonstrated by the synthesis of $\mathbf{3 b j}$ and $\mathbf{3 b k}$.

Next, we monitored the transformation of three thioesters with varying steric bulk (Figure 1a). The conversion of substrate 1a was completed in less than $1 \mathrm{~min}$. Also, we confirmed that indeed the substituent at the $\alpha$-position has a strong influence, possibly due to steric interaction with the catalyst and the resulting inhibition. To underline this effect on tertiary substrates, the reaction solution containing $\mathbf{1 n}$ was treated with additional precatalyst after 30 minutes and increased conversion was observed (Figure 1b). The reaction progress of the coupling of 1a in degassed and non-degassed THF was compared (Figure 1c). The experiment showed that the small decrease of yield and conversion in degassed solvents occurs before the reaction as 
the difference is consistent and independent of the amount of manganese reagent added.

Furthermore, we investigated the catalytic activity of the preformed catalyst-transmetalating reagent mixture as a function of time until the substrate was added (Figure 3d). As expected, the catalytic conversion and yield decreased over time, although even after $75 \mathrm{~min}$ of treating the precatalyst with manganese reagent the catalytic activity could still be observed. Although nondegassed THF was used, a difference in conversion and yield was observed, decreasing over time of treatment of precatalyst with transmetallation reagent. We thereby suggest that the trace
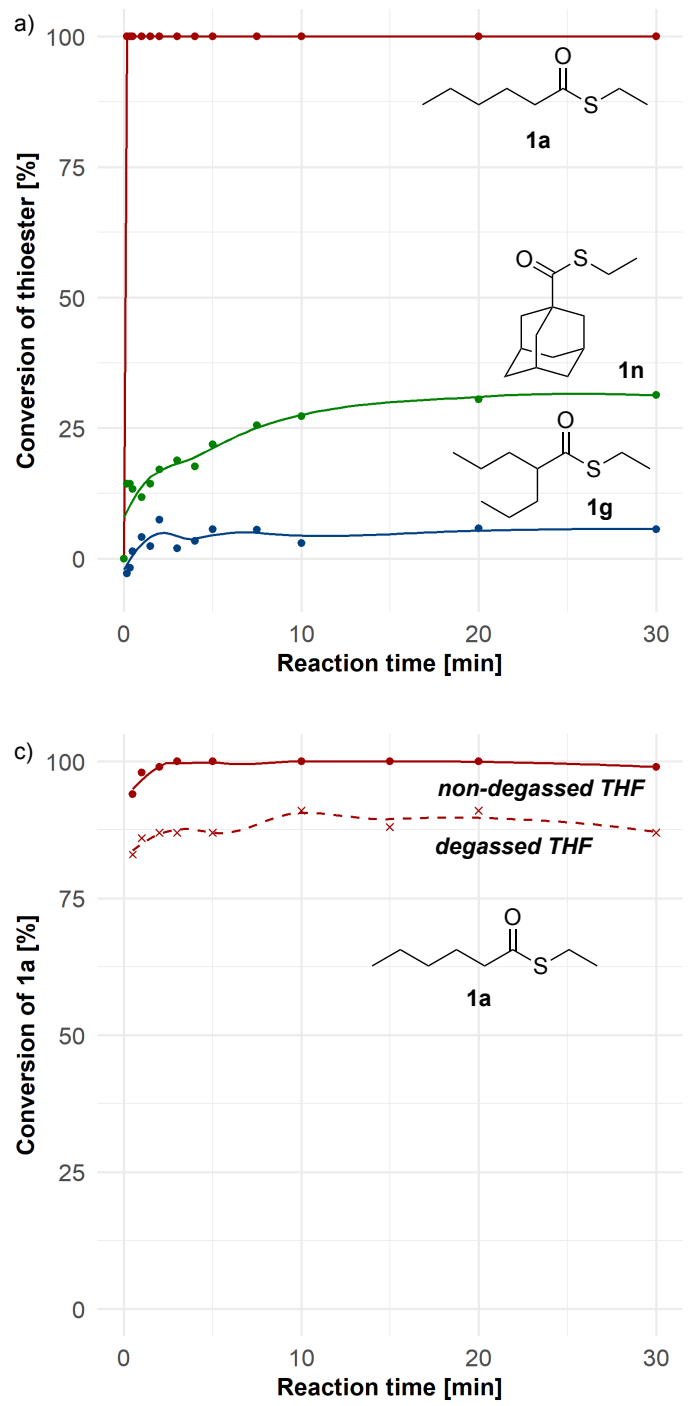

amount of oxygen, which can be obtained by either not degassing the solvent or bubbling small amounts of air through degassed solvent, inhibits the formation of a possible unproductive iron species, which forms upon introducing the transmetallating reagent to the solution and fades over time. Also, it was tested whether the low conversion/yield was due to a decomposition of manganese reagent catalyzed by iron, as postulated by Kochi ${ }^{[18]}$ for dialkyl manganese species, or by loss of catalyst. We found that additional manganese reagent didn't elevate reaction yields. Therefore, the loss in yield is assumed to be related to a loss of catalyst by reductive processes.
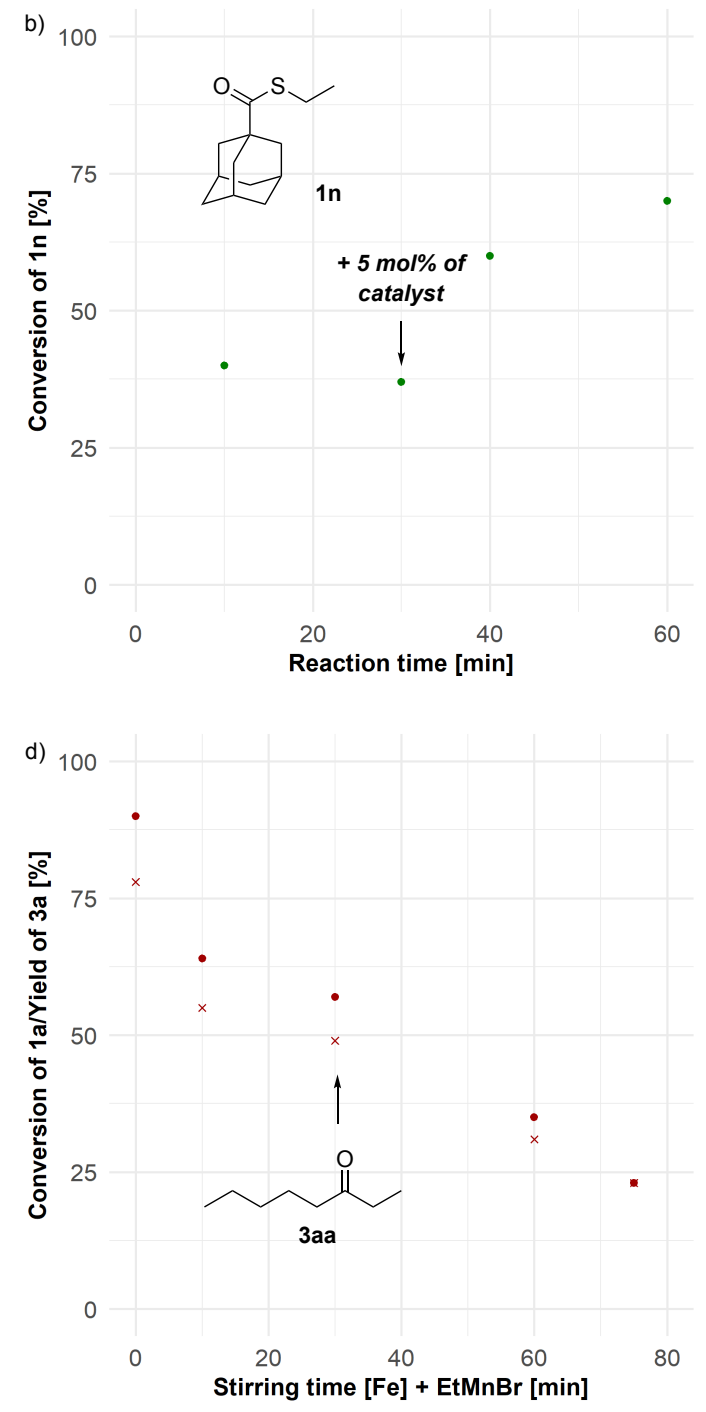

Figure 1. Reaction progress of following transformations: a) Conversion of different thioesters under catalytic conditions; b) Conversion of $1 \mathrm{n}$ with a second addition of precatalyst after $30 \mathrm{~min}$; c) Conversion of 1a and yield of 3aa without oxygen. d) Influence of the time of stirring of the precatalyst with ethylmanganese bromide on the coupling of $\mathbf{1 a}$.

A mechanistic proposal would be premature at the moment. Related iron-catalyzed couplings of organomagnesium reagents with electrophiles such as arylhalides are known since the pioneering studies by Kochi in the 1970 s, ${ }^{[25]}$ but only recently more light was shed on the mechanistic diversity of this chemistry, which is caused by the possibility of the formation of multiple iron species with different spin and oxidation states. ${ }^{[26]}$ It was found that not only the nature of precatalyst (presence of ligand), but also that of the organometallic reagent plays a decisive role in the formation of active catalytic species. In our case, the situation will be even more complex due to the presence of a second redox active metal and the liberated thiolate, which might coordinate to the metals. It is likely that the activation of the catalyst will occur via multiple pathways. Based on the observed reactivity of the 
organomanganese reagents, the reduction of the precatalyst by $\beta$-hydride elimination seems to be the primary mechanism. ${ }^{[27]}$

\section{Conclusion}

In summary, we have developed an iron-catalyzed cross-coupling of thioesters with organomanganese reagents. The method tolerates a broad range of functional groups and stands out due to its simplicity with the necessity of using non-degassed solvent and short reaction times. The reaction is sensitive towards the steric demands of the carboxylic and the thiol moiety as well as the organomanganese reagent, but conversion can be enforced by changing reaction conditions. Based on this steric dependence, we have demonstrated selective transformation for specific thioester motifs enabling high regioselectivity. Moreover, cases of tandem reactivity such as Kumada coupling or enamine formation were explored. Our experiments point to the conclusion that the combination of trace oxygen and aliphatic, $\beta$-hydrogen containing manganese compounds suppress the formation of unproductive iron species. Studies towards the examination of the nature of the reactive iron species are underway. Thus, this work does not only introduce a new methodology to synthesize ketones, it also expands the scope of iron catalysis and organomanganese chemistry.

\section{Acknowledgements}

We thank R. Richter, L. Biehler, S. Jeltsch, C. Wilhelm and R. Kern for the synthesis of several compounds as well as for their tenacious endeavours to research facets of this topic that weren't further pursued. Financial support from Boehringer Ingelheim Stiftung (Exploration Grant) and the University of Tübingen is gratefully acknowledged.

Keywords: iron catalysis • Fukuyama • organomanganese reagents $\cdot$ cross coupling $\bullet$ thioesters

[1] V. Hirschbeck, P. H. Gehrtz, I. Fleischer, Chem. Eur. J. 2018, 24, 7092 7107.

[2] a) H. Tokuyama, S. Yokoshima, T. Yamashita, T. Fukuyama, Tetrahedron Lett. 1998, 39, 3189-3192; b) H. Tokuyama, S. Yokoshima T. Yamashita, L. Shao-Cheng, L. Leping, T. Fukuyama, J. Braz. Chem. Soc. 1998, 9, 381-387.

[3] a) M. Seki, M. Hatsuda, Y. Mori, S.-i. Yoshida, S.-i. Yamada, T. Shimizu, Chem. Eur. J. 2004, 10, 6102-6110; b) H. Ueda, H. Satoh, K. Matsumoto, K. Sugimoto, T. Fukuyama, H. Tokuyama, Angew. Chem., Int. Ed. 2009 , 48, 7600-7603; c) D. S. Siegel, G. Piizzi, G. Piersanti, M. Movassaghi, J.Org. Chem. 2009, 74, 9292-9304; d) S.-Q. Tang, J. Bricard, M. Schmitt, F. Bihel, Org. Lett. 2019, 21, 844-848; e) J. Talode, D. Kato, H. Nagae, H. Tsurugi, M. Seki, K. Mashima, J. Org. Chem. 2020, 85, 12382-12392.

[4] a) Y. Mori, M. Seki, Adv. Synth. Catal. 2007, 349, 2027-2038; b) K. Kunchithapatham, C. C. Eichman, J. P. Stambuli, Chem. Commun. 2011, 47, 12679-12681; c) A. H. Cherney, S. E. Reisman, Tetrahedron 2014, 70, 3259-3265.

[5] a) T. Shimizu, M. Seki, Tetrahedron Lett. 2002, 43, 1039-1042; b) Y. Zhang, T. Rovis, J. Am. Chem. Soc. 2004, 126, 15964-15965; c) P. H. Gehrtz, P. Kathe, I. Fleischer, Chem. Eur. J. 2018, 24, 8774-8778.

[6] F. H. Lutter, L. Grokenberger, M. S. Hofmayer, P. Knochel, Chem. Sci. 2019, 10, 8241-8245.
[7] L. S. Liebeskind, J. Srogl, J. Am. Chem. Soc. 2000, 122, 11260-11261.

[8] V. P. Mehta, A. Sharma, E. Van der Eycken, Adv. Syn. Catal. 2008, 350, 2174-2178.

[9] Y. Yu, L. S. Liebeskind, J. Org. Chem. 2004, 69, 3554-3557.

[10] R. Wittenberg, J. Srogl, M. Egi, L. S. Liebeskind, Org. Lett. 2003, 5, 30333035.

[11] B. W. Fausett, L. S. Liebeskind, J. Org. Chem. 2005, 70, 4851-4853.

[12] R. Oost, A. Misale, N. Maulide, Angew. Chem. Int. Ed. 2016, 55, 45874590 .

[13] a) C. Cardellicchio, V. Fiandanese, G. Marchese, L. Ronzini, Tetrahedron Lett. 1985, 26, 3595-3598; b) W. Oppolzer, C. Darcel, P. Rochet, S. Rosset, J. De Brabander, Helv. Chim. Acta 1997, 80, 13191337.

[14] G. Cahiez, C. Duplais, J. Buendia, Chem. Rev. 2009, 109, 1434-1476.

[15] a) G. Cahiez, D. Bernard, J. F. Normant, Synthesis 1977, 1977, 130-133; b) G. Cahiez, J. F. Normant, Tetrahedron Lett. 1977, 18, 3383-3384; c) G. Cahiez, A. Alexakis, J. F. Normant, Synth. Commun. 1979, 9, 639645; d) G. Cahiez, Tetrahedron Lett. 1981, 22, 1239-1242; e) G. Cahiez, M. Alami, Tetrahedron Lett. 1989, 30, 3541-3544; f) G. Cahiez, M. Alami, Tetrahedron Lett. 1990, 31, 7423-7424.

[16] G. Cahiez, M. S., Pure Appl. Chem. 1996, 68, 53-60.

[17] a) A. D. Benischke, A. Desaintjean, T. Juli, G. Cahiez, P. Knochel, Synthesis 2017, 49, 5396-5412; b) M. S. Hofmayer, J. M. Hammann, G. Cahiez, P. Knochel, Synlett 2018, 29, 65-70; c) A. Desaintjean, S. Belrhomari, L. Rousseau, G. Lefèvre, P. Knochel, Org. Lett. 2019, 21, 8684-8688; d) L. Rousseau, A. Desaintjean, P. Knochel, G. Lefèvre, Molecules 2020, 25, 723.

[18] M. Tamura, J. Kochi, J. Organomet. Chem. 1971, 29, 111-129.

[19] M. Uzelac, P. Mastropierro, M. de Tullio, I. Borilovic, M. Tarrés, A. R. Kennedy, G. Aromí, E. Hevia, Angew. Chem. Int. Ed. 2021, 60, 32473253.

[20] a) G. A. Molander, B. J. Rahn, D. C. Shubert, S. E. Bonde, Tetrahedron Lett 1983, 24, 5449-5452; b) A. Fürstner, A. Leitner, Angew. Chem. Int. Ed. 2002, 41, 609-612.

[21] a) G. Cahiez, A. Moyeux, J. Buendia, C. Duplais, J. Am. Chem. Soc. 2007, 129, 13788-13789; b) G. Cahiez, C. Duplais, J. Buendia, Angew. Chem. Int. Ed. 2009, 48, 6731-6734; c) A. Bottoni, G. Cahiez, M. Calvaresi, A. Moyeux, P. Giacinto, G. P. Miscione, J. Organomet. Chem. 2016, 814, 25-34.

[22] W. Y. Lee, Y. S. Lee, S. Y. Jang, S. Y. Lee, Bull. Korean Chem. Soc. 1991, 12, 26-31.

[23] L. S. Chen, C. Tamborski, J. Fluorine Chem. 1981, 19, 43-53.

[24] a) T. Parchomyk, S. Demeshko, F. Meyer, K. Koszinowski, J. Am. Chem. Soc. 2018, 140, 9709-9720; b) S. B. Muñoz, S. L. Daifuku, J. D. Sears, T. M. Baker, S. H. Carpenter, W. W. Brennessel, M. L. Neidig, Angew. Chem. Int. Ed. 2018, 57, 6496-6500.

[25] a) M. Tamura, J. Kochi, J. Organomet. Chem. 1971, 31, 289-309; b) M. Tamura, J. K. Kochi, J. Am. Chem. Soc. 1971, 93, 1487-1489; c) R. S. Smith, J. K. Kochi, J. Org. Chem. 1976, 41, 502-509.

[26] a) M. H. Al-Afyouni, K. L. Fillman, W. W. Brennessel, M. L. Neidig, J. Am. Chem. Soc. 2014, 136, 15457-15460; b) A. Hedström, Z. Izakian, I. Vreto, C.-J. Wallentin, P.-O. Norrby, Chem. Eur. J. 2015, 21, 5946-5953; c) S. B. Muñoz, S. L. Daifuku, W. W. Brennessel, M. L. Neidig, J. Am. Chem. Soc. 2016, 138, 7492-7495; d) T. Parchomyk, K. Koszinowski, Chem. Eur. J. 2016, 22, 15609-15613; e) M. L. Neidig, S. H. Carpenter, D. J. Curran, J. C. DeMuth, V. E. Fleischauer, T. E. lannuzzi, P. G. N. Neate, J. D. Sears, N. J. Wolford, Acc. Chem. Res. 2019, 52, 140-150; f) P. G. N. Neate, M. L. Neidig, in Catalysis with Earth-abundant Elements, The Royal Society of Chemistry, 2021, pp. 231-245.

[27] a) B. Bogdanović, M. Schwickardi, Angew. Chem., Int. Ed. 2000, 39, 4610-4612; b) A. Fürstner, H. Krause, C. W. Lehmann, Angew. Chem., Int. Ed. 2006, 45, 440-444; c) A. Fürstner, R. Martin, H. Krause, G. Seidel, R. Goddard, C. W. Lehmann, J. Am. Chem. Soc. 2008, 130, 8773-8787. 